Biorheology, 1968, Vol. 5, p. 79. Pergamon Press. Printed in Great Britain.

\title{
FIFTH INTERNATIONAL CONGRESS ON RHEOLOGY
}

\author{
Kyoto International Conference Hall, Kyoto, JAPAN \\ Monday, October 7-Friday, October 11, 1968 \\ This Congress will be held \\ under the auspices of \\ THE INTERNATIONAL COMMITTEE ON RHEOLOGY \\ and the sponsorship of \\ THE SCIENCE COUNCIL OF JAPAN \\ with \\ THE SOCIETY OF MATERIALS SCIENCE, JAPAN \\ and \\ THE SOCIETY OF POLYMER SCIENCE, JAPAN \\ as host organizations \\ Honorary President: Professor John D. FerRY \\ Co-Chairmen of the Organizing Committee: \\ Professor MASAO Horio, Kyoto \\ and \\ Professor Bun-IChi Tamamushi, Tokyo
}

Biorheology is included among the topics discussed.

No official language will be designated, but English is recommended.

The scientific program of the ICR will consist of general lectures, invited papers, and contributed papers.

Those who wish to attend the ICR are requested to write to the Co-Chairman of the Organizing Committee, Professor Masao Horio, before October 1, 1967 (deadline).

Participants who wish to contribute papers should send abstracts of approximately 300 words to the Co-Chairman Professor Masao Horio, Department of Polymer Chemistry, Kyoto University, Kyoto, Japan, before March 1, 1968 (deadline).

The members of the Organizing Committee of the Fifth International Congress on Rheology are as follows:

Co-Chairmen:

Prof. MASAO HORIO

Prof. Bun-ICHI TAMAMUSH

Executive Members:

Dr. EIICHI FuKadA

Prof. RempeI GoTOH

Prof. Hirotaro Kambe

Prof. SYOTEN OKa

Prof. Shigeharu ONOGi. 